\title{
Complete Spectral Assignment of Poly( $N$-Vinylcarbazole-co-Methyl Acrylate)s by NMR Spectroscopy
}

\author{
Ajaib Singh BRAR ${ }^{\dagger}$ and Manpreet KAUR \\ Department of Chemistry, Indian Institute of Technology, Delhi, Hauz Khas, \\ New Delhi 110016, India
}

(Received October 22, 2001; Accepted March 7, 2002)

\begin{abstract}
The copolymers of $N$-vinylcarbazole/methyl acrylate (V/M) of different compositions were prepared by solution polymerisation using 2,2'-Azobisisobutyronitrile (AIBN) as an initiator and their composition was determined from quantitative ${ }^{13} \mathrm{C}\left\{{ }^{1} \mathrm{H}\right\}$ NMR spectroscopy. Reactivity ratios for the comonomers were calculated using the Kelen-Tudos (KT) and non-linear error in variable methods (EVM). The complete spectral assignment of the overlapping ${ }^{1} \mathrm{H}$ and ${ }^{13} \mathrm{C}\left\{{ }^{1} \mathrm{H}\right\}$ spectra of the copolymers were done with the help of Distortionless Enhancement by Polarization Transfer (DEPT), two dimensional heteronuclear single quantum correlation (HSQC) and total correlated spectroscopy (TOCSY). The assignments of various compositional sequences were done in the carbon resonance signals of the methoxy region of $\mathrm{M}$ unit, the methine region of both $\mathrm{V}$ and $\mathrm{M}$ units and the methylene region of both $\mathrm{V}$ and $\mathrm{M}$ units.

KEY WORDS Poly( $N$-vinylcarbazole-co-methyl acrylate)s / Two Dimensional Nuclear Magnetic Resonance (2D NMR) Spectroscopy / Microstructure /
\end{abstract}

Poly( $N$-vinylcarbazole) (PVK) has been the subject of intensive investigation because it is one of the most sensitive photoconductive organic polymers. ${ }^{1,2}$ It has important applications in electrophotography, microlithography, electrochromic display devices, photoelectric devices, electroluminescent displays, and photothermoplastic imaging. ${ }^{3}$ PVK is a stiff, brittle substance with poor mechanical and processing characteristics. Copolymerization with suitable monomers could soften the resulting product leading to better film properties and improve its mechanical properties. The copolymerization of $N$-vinylcarbazole with monomers like alkyl acrylates and alkyl methacrylates has been studied by several investigators. ${ }^{4-6}$

The determination of microstructure in copolymers is of value in establishing structure-property relationship. ${ }^{7}$ It is well known that NMR spectroscopy is probably the most effective method for characterizing the microstructure of polymers. ${ }^{8-10}$ Crone and Natanso$\mathrm{hn}^{11}$ have reported the NMR analysis of microstructure of poly(methyl acrylate- $c o-N$-vinylcarbazole). They have assigned the aliphatic and aromatic region in the proton spectra and aromatic region in the carbon spectra of the copolymers. However, some of the carbon and proton signals of the carbazole ring are erroneously assigned by them. They have reported the sequence distribution in the copolymers using $\mathrm{C}-1,8 \mathrm{a}$ and $\mathrm{H}-1$ resonance signals of the carbazole ring and the carbonyl carbon resonance signal of the $\mathrm{M}$ unit in the copolymer. However, they have not described the sequence distribution using the aliphatic region of the copolymer

${ }^{\dagger}$ To whom all correspondence should be addressed. spectra.

Dais et al. ${ }^{12}$ have reported the complete assignments of ${ }^{1} \mathrm{H}$ and ${ }^{13} \mathrm{C}$ spectra of PVK with the help of two-dimensional NMR techniques. In our earlier publication, ${ }^{13}$ we reported the microstructure of $N$ vinylcarbazole/vinyl acetate copolymers using one and two-dimensional NMR spectroscopy. In continuation of our earlier work, in this paper we report the complete assignment of ${ }^{1} \mathrm{H}$ and ${ }^{13} \mathrm{C}\left\{{ }^{1} \mathrm{H}\right\}$ NMR spectra of $N$-vinylcarbazole/methyl acrylate copolymers with the help of Distortionless Enhancement by Polarization Transfer (DEPT), two-dimensional heteronuclear single quatum correlation (HSQC) and total correlated spectroscopy (TOCSY) NMR experiments. The methoxy region of the $\mathrm{M}$ unit and the methine region of both $\mathrm{V}$ and $\mathrm{M}$ units in the copolymers are assigned to triad compositional sequences and the methylene region of both $\mathrm{V}$ and $\mathrm{M}$ units are assigned to dyad compositional sequences. The various configurational arrangements in the methylene region of $\mathrm{M}$ unit are also assigned. The reactivity ratios of the comonomers are calculated using Kelen-Tudos (KT) ${ }^{14}$ and the nonlinear error in variable $(\mathrm{EVM})^{15}$ methods.

\section{EXPERIMENTAL}

$N$-vinylcarbazole (Aldrich) was used as supplied and methyl acrylate $(\mathrm{CDH})$ was distilled under reduced pressure and stored below $5^{\circ} \mathrm{C}$. A series of $N$ vinylcarbazole/methyl acrylate (V/M) copolymers containing different mol fractions of $N$-vinylcarbazole in feed, were prepared by solution polymerization using 
Table I. Copolymer composition and molecular weight averages of $N$-vinylcarbazole/methyl acrylate copolymers

\begin{tabular}{|c|c|c|c|c|c|c|}
\hline Sample & $f_{\mathrm{V}}$ & $F_{\mathrm{V}}$ & $\begin{array}{c}\% \% \\
\text { Conversion }\end{array}$ & $\frac{\bar{M}_{\mathrm{n}} \times 10^{-5}}{\mathrm{~g} \mathrm{~mol}^{-1}}$ & $\frac{\bar{M}_{\mathrm{w}} \times 10^{-5}}{\mathrm{~g} \mathrm{~mol}^{-1}}$ & Polydispersity \\
\hline VM1 & 0.15 & 0.14 & 7.0 & 2.36 & 4.47 & 1.89 \\
\hline VM2 & 0.20 & 0.23 & 7.5 & 3.85 & 5.82 & 1.51 \\
\hline VM3 & 0.30 & 0.30 & 8.5 & 4.03 & 5.82 & 1.44 \\
\hline VM4 & 0.40 & 0.38 & 5.5 & 3.84 & 5.51 & 1.43 \\
\hline VM5 & 0.50 & 0.39 & 6.5 & 4.61 & 6.07 & 1.32 \\
\hline VM6 & 0.60 & 0.44 & 7.5 & 4.31 & 5.77 & 1.34 \\
\hline VM7 & 0.70 & 0.48 & 7.0 & 4.83 & 6.07 & 1.25 \\
\hline VM8 & 0.90 & 0.57 & 8.0 & 4.51 & 5.97 & 1.32 \\
\hline VM9 & 0.95 & 0.70 & 8.5 & 4.25 & 5.69 & 1.33 \\
\hline
\end{tabular}

$f_{\mathrm{V}}$ is the mol fractions of $\mathrm{V}$ in feed. $F_{\mathrm{V}}$ is the mol fractions of $\mathrm{V}$ in the copolymer. $\bar{M}_{\mathrm{n}}$ and $\bar{M}_{\mathrm{w}}$ are number average and weight average molecular weight of copolymers calculated using Gel permeation chromatography technique.

benzene as a solvent and AIBN as an initiator at $60^{\circ} \mathrm{C}$. The conversion was kept below $10 \%$ by precipitating the copolymers in methanol. The copolymers were further purified using chloroform/methanol.

All the $1 \mathrm{D}\left({ }^{1} \mathrm{H},{ }^{13} \mathrm{C}\left\{{ }^{1} \mathrm{H}\right\}\right.$ and DEPT) and 2D (HSQC and TOCSY (18 ms)) NMR spectra of the copolymers were recorded in $\mathrm{CDCl}_{3}$ on Bruker $300 \mathrm{MHz} \mathrm{DPX}$ spectrometer at $25^{\circ} \mathrm{C}$ using the concentration of 10 $15 \%(\mathrm{w} / \mathrm{v})$ and the standard pulse sequences as reported in our earlier papers. ${ }^{16,17}$ The copolymer composition was determined experimentally by quantitative ${ }^{13} \mathrm{C}\left\{{ }^{1} \mathrm{H}\right\}$ NMR spectroscopy using inverse gated decoupling pulse program where relaxation delay was kept $10 \mathrm{~s}$. The molecular weight averages were determined by GPC (Gel Permeation Chromatography) using the polystyrene as narrow standards.

\section{RESULTS AND DISCUSSION}

\section{Reactivity Ratios Determination}

The compositions of V/M copolymers were determined from quantitative ${ }^{13} \mathrm{C}\left\{{ }^{1} \mathrm{H}\right\}$ NMR spectroscopy using standard pulse program. The comonomer mol fractions in the feed and in the copolymer, the percentage conversion and the molecular weight averages are shown in Table I. The copolymer composition data was used to calculate the terminal model reactivity ratios using the Kelen-Tudos (KT) method. ${ }^{14}$ These reactivity ratio values along with the copolymer composition data were used to calculate the reactivity ratios from the non-linear error in variable (EVM) program. ${ }^{15}$ The values of reactivity ratios obtained from Kelen-Tudos (KT) and non-linear error in variable method (EVM) are $r_{\mathrm{V}}=0.07 \pm 0.03, r_{\mathrm{M}}=0.65 \pm 0.13$ and $r_{\mathrm{V}}=0.08$, $r_{\mathrm{M}}=0.73$ respectively.

\section{${ }^{13} C\left\{{ }^{1} H\right\}$ NMR Studies}

Crone and Natansohn have erroneously assigned carbon 3, 8a and 1a of the carbazole ring in the copolymer spectrum. ${ }^{11}$ Correct assignments of the carbazole ring in poly( $N$-vinylcarbazole $)$ are reported by Dias et al. ${ }^{12}$ The ${ }^{13} \mathrm{C}\left\{{ }^{1} \mathrm{H}\right\}$ NMR spectrum of $N$-vinylcarbazole/methyl acrylate $(\mathrm{V} / \mathrm{M})$ copolymer $\left(F_{\mathrm{V}}=0.44\right)$ recorded in $\mathrm{CDCl}_{3}$ is shown in Figure 1 along with the complete signal assignments. The carbonyl carbon of $\mathrm{M}$ unit resonates around $\delta 173.5-$ $176.0 \mathrm{ppm}$. The aromatic carbons of the $\mathrm{V}$ region resonate at $\delta 108.5$ (C-1), $\delta 111.0(\mathrm{C}-8), \delta 119.0(\mathrm{C}-3,6)$, $\delta 119.8(\mathrm{C}-4), \delta 120.2(\mathrm{C}-5), \delta 122.0(\mathrm{C}-4 \mathrm{a}), \delta 123.8$ (C-5a), $\delta 124.5-127.0(\mathrm{C}-2,7), \delta 138.0(\mathrm{C}-8 \mathrm{a})$, and $\delta$ $141.0(\mathrm{C}-1 \mathrm{a}) \mathrm{ppm}$. These assignments are made with the help of the ${ }^{13} \mathrm{C}\left\{{ }^{1} \mathrm{H}\right\}$ NMR spectra of the homopolymers. The spectral region around $\delta 32.5-37.0 \mathrm{ppm}$ can be assigned to the methylene carbon of the both $\mathrm{V}$ and $\mathrm{M}$ units and the region around $\delta 37.7-41.2 \mathrm{ppm}$ can be assigned to the methine carbon of the $\mathrm{M}$ unit. These assignments are confirmed by the DEPT-135 NMR spectrum $\left(F_{\mathrm{V}}=0.44\right)$ as shown in Figure 2a where methylene carbon signals appear in the negative phase and methine and methyl carbon signals appear in positive phase. The methoxy region of the M unit and the methine region of the $\mathrm{V}$ unit in the copolymer overlap in the region around $\delta 49.0-53.0 \mathrm{ppm}$. DEPT-90 NMR spectrum $\left(F_{\mathrm{V}}=0.44\right.$, Figure $\left.2 \mathrm{~b}\right)$ was recorded to resolve them. The methine carbon resonances of the $\mathrm{V}$ unit are assigned around $\delta 49.5-54.0 \mathrm{ppm}$.

The methine carbon resonances of both $\mathrm{V}$ and $\mathrm{M}$ units of the copolymer are sensitive to compositional sequences. The expanded region of methine carbon of the V unit in the DEPT-90 spectra of V/M copolymers with different mole fractions of $\mathrm{V}$ and the corresponding homopolymer is shown in Figure $3(\mathrm{~b}-\mathrm{e})$. The signals resonating around $\delta 48.20-50.30 \mathrm{ppm}$ increase in intensity with increase in the $\mathrm{V}$ content in the copolymer, the signals resonating around $\delta 50.30-51.10 \mathrm{ppm}$ first show increase and then decrease in intensity with increase in $\mathrm{V}$ content in the copolymer and the signals resonating around $\delta 51.10-51.90 \mathrm{ppm}$ show decrease in 


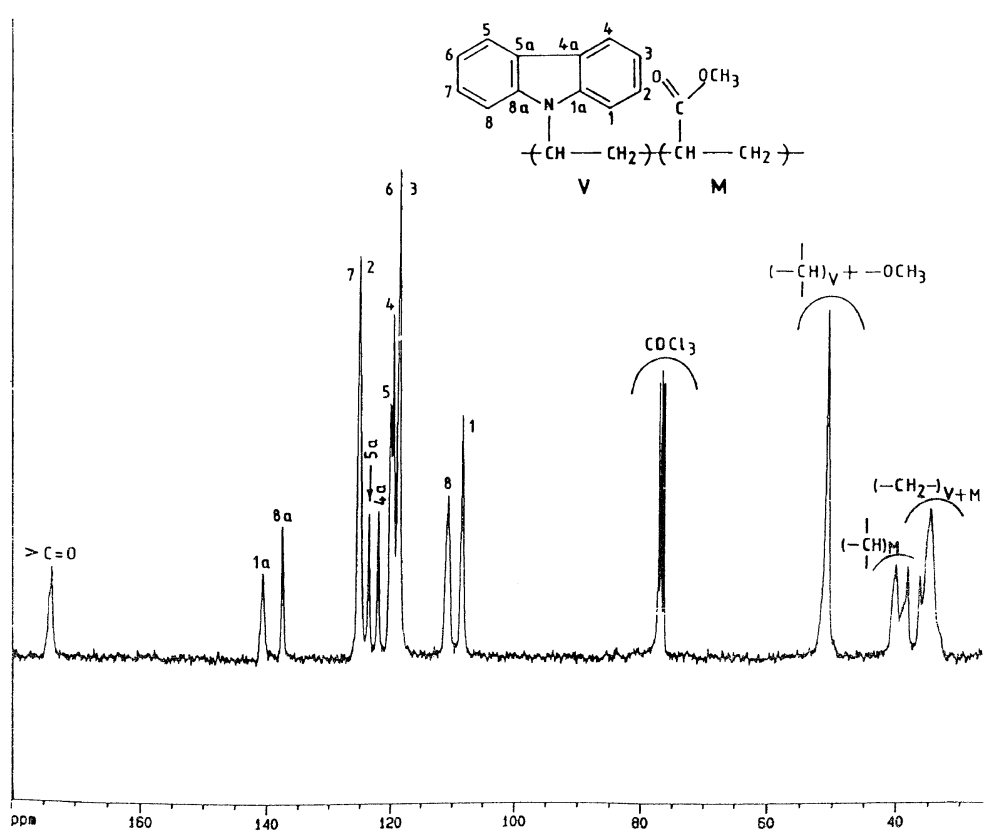

Figure 1. The ${ }^{13} \mathrm{C}\left\{{ }^{1} \mathrm{H}\right\}$ NMR spectrum of V/M copolymer of the composition $F_{\mathrm{V}}=0.44$.

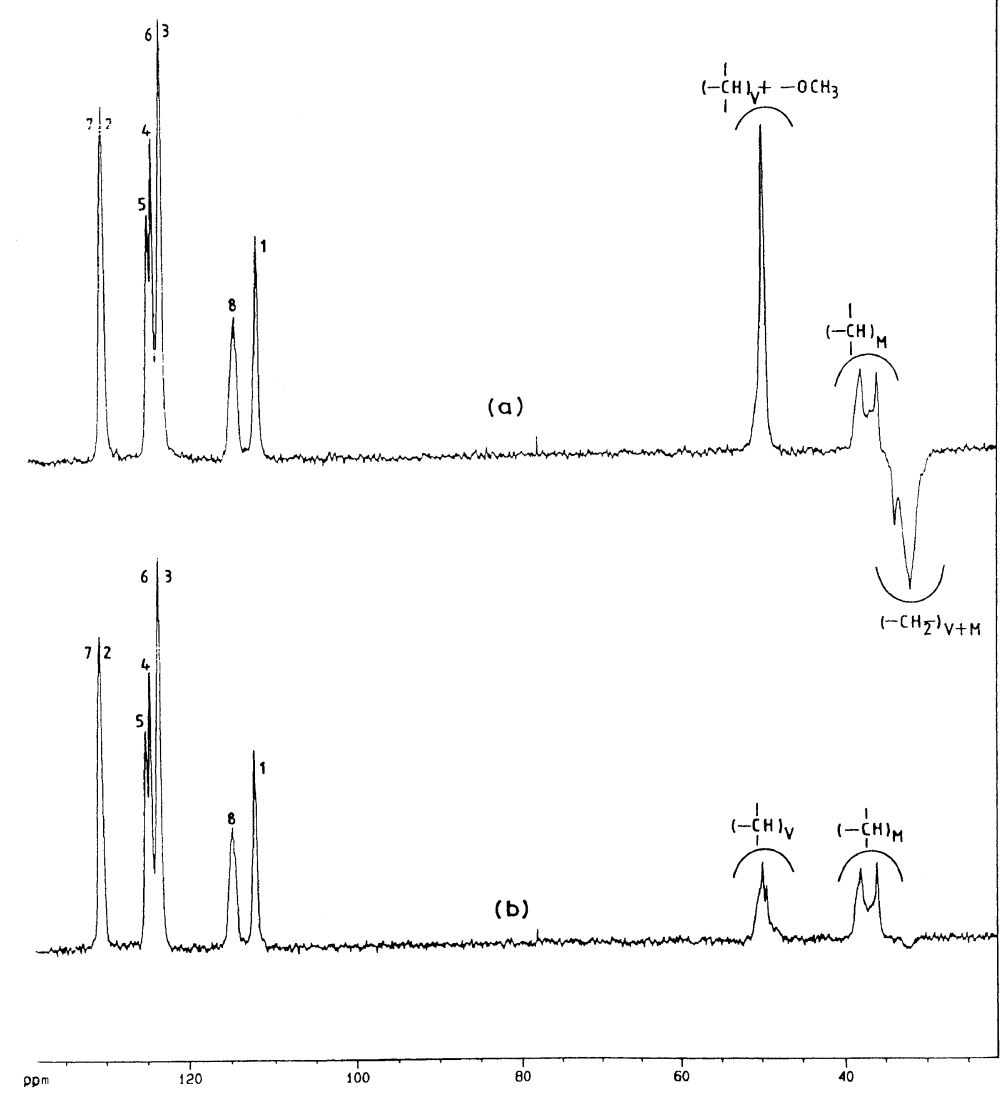

Figure 2. (a) The DEPT-135 NMR spectrum of V/M copolymer of the composition $F_{\mathrm{V}}=0.44$. (b) The DEPT-90 NMR spectrum of $\mathrm{V} / \mathrm{M}$ copolymer of the composition $F_{\mathrm{V}}=0.44$.

intensity with increase in $\mathrm{V}$ content in the copolymer. Thus on the basis of change in intensity of the signals with change in the copolymer composition and by comparing with the methine region of the homopolymer, the three resonating signals around $\delta 48.20-50.30, \delta 50.30$
51.10 , and $\delta 51.10-51.90 \mathrm{ppm}$ are assigned to $\mathrm{VVV}$, VVM, and MVM triads, respectively. Similarly, the regions around $\delta 42.0-40.8, \delta 40.8-39.8$, and $\delta 39.8-$ $38.0 \mathrm{ppm}$ in the expanded region of the methine carbon of the $\mathrm{M}$ unit (Figure $3(\mathrm{a}-\mathrm{d})$ are assigned to MMM, 


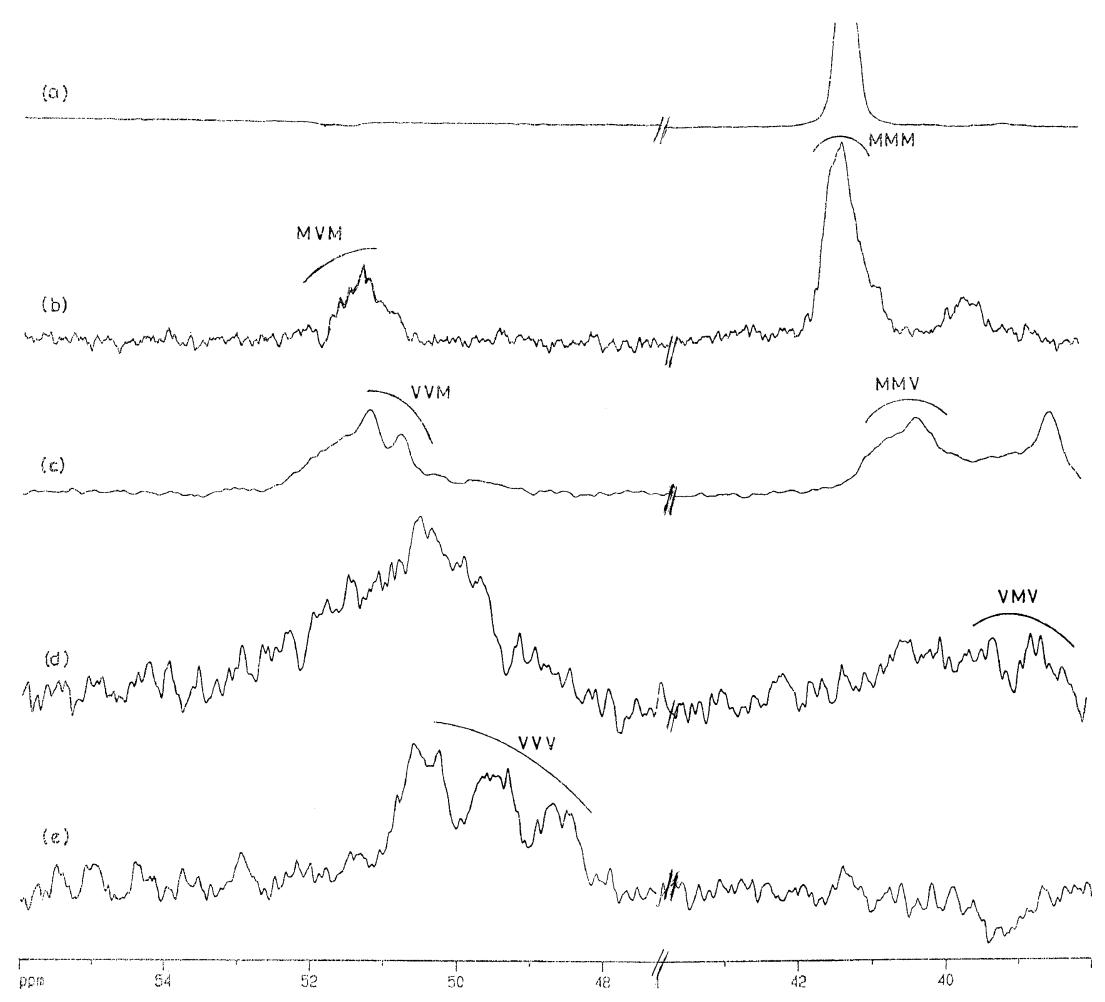

Figure 3. The expanded DEPT-90 NMR spectrum showing methine carbon resonance signals of the M and the V unit of V/M copolymers of the composition (a) poly(methyl acrylate), (b) $F_{\mathrm{V}}=0.14$, (c) $F_{\mathrm{V}}=0.44$, (d) $F_{\mathrm{V}}=0.70$, and (e) poly $(N$-vinylcarbazole).
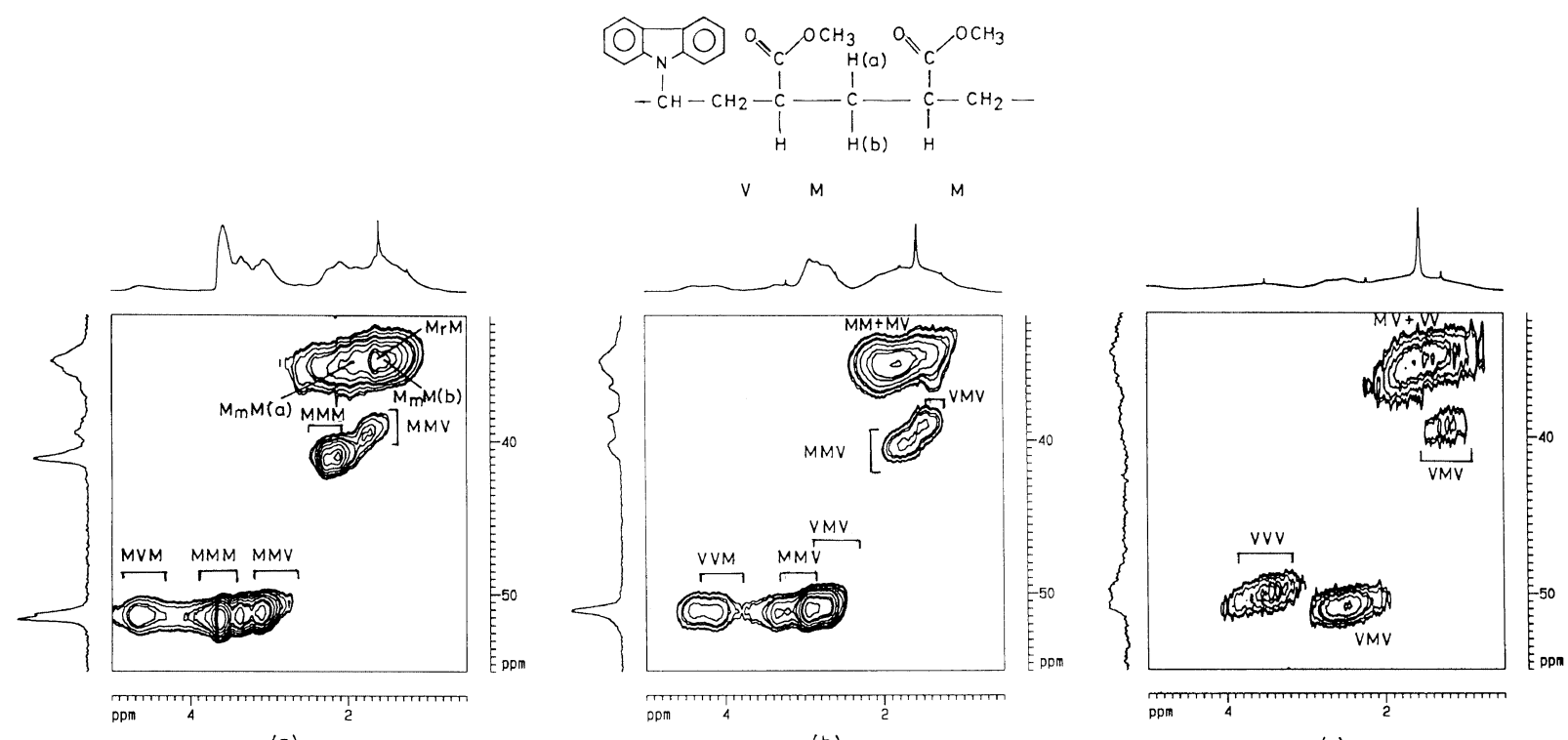

Figure 4. The expanded HSQC spectrum showing the methoxy, the methine, and the $\beta$-methylene region of V/M copolymers of the composition (a) $F_{\mathrm{V}}=0.14$, (b) $F_{\mathrm{V}}=0.44$, and (c) $F_{\mathrm{V}}=0.70$.

MMV, and VMV triads respectively.

\section{D-HSQC NMR Spectra Studies}

The expanded aliphatic region of the HSQC spectra are shown in Figure $4(\mathrm{a}-\mathrm{c})\left(F_{\mathrm{V}}=0.14,0.44\right.$, and $0.70)$. The methine group in both $\mathrm{M}$ and $\mathrm{V}$ units show compositional sensitivity. The methine resonances of $\mathrm{V}$ unit, around $\delta 51.5 / 4.80-4.45, \delta 51.0 / 4.45-3.90$, and $\delta 50.0 / 3.90-3.10 \mathrm{ppm}$ are assigned to triad composi- tional sequences MVM, MVV, and VVV respectively on the basis of change in intensity with the change in copolymer composition and the assignments done in the poly $(N$-vinylcarbazole) HSQC spectrum. Similarly, the methine resonances of $\mathrm{M}$ unit, in the region $\delta 42.7-$ $39.4 / 2.50-2.00, \delta 41.5-39.0 / 2.00-1.50$, and $\delta 40.5-$ $38.0 / 1.50-1.05 \mathrm{ppm}$ are assigned to triad compositional sequences MMM, MMV, and VMV respectively on the basis of change in intensity with the change in 
Table II. Assignments of Resonance signals of 2D HSQC NMR spectra

\begin{tabular}{clc}
\hline S. No. & Peak Assignments & $\begin{array}{c}\text { Peak Positions/ppm } \\
{ }^{13} \mathrm{C} /{ }^{1} \mathrm{H}\end{array}$ \\
\hline & $(\mathrm{CH})_{\mathrm{V}}$ & $51.5 / 4.80-4.45$ \\
2 & $\mathrm{MVM}$ & $51.0 / 4.45-3.90$ \\
3 & $\mathrm{VVM}$ & $50.0 / 3.90-3.10$ \\
& $\mathrm{VVV}$ & \\
& & \\
4 & $\left(\mathrm{OCH}_{3}\right)_{\mathrm{M}}$ & $53.0-50.0 / 3.85-3.25$ \\
5 & $\mathrm{MMM}$ & $52.5-49.8 / 3.25-2.80$ \\
6 & $\mathrm{MMV}$ & $52.4-49.5 / 3.00-2.00$ \\
& $\mathrm{VMV}$ & \\
7 & $(\mathrm{CH})_{\mathrm{M}}$ & $42.7-39.4 / 2.50-2.00$ \\
8 & $\mathrm{MMM}$ & $41.5-39.0 / 2.00-1.50$ \\
9 & $\mathrm{MMV}$ & $40.5-38.0 / 1.50-1.05$ \\
& $\mathrm{VMV}$ & $35.0 / 1.90$ \\
10 & $(\mathrm{CH})$ & $35.0 / 1.65$ \\
11 & $\mathrm{MmM}(\mathrm{a})$ & $35.0 / 1.45$ \\
\hline
\end{tabular}

copolymer composition and the assignments done in the poly(methyl acrylate) HSQC spectrum.

The methoxy region of the $\mathrm{M}$ unit in the ${ }^{13} \mathrm{C}\left\{{ }^{1} \mathrm{H}\right\}$ NMR spectrum is overlapped with the methine region of the $\mathrm{V}$ unit and can be assigned with the help of HSQC spectra (Figure $4(\mathrm{a}-\mathrm{c})$, Table II) as this region shows triad compositional sensitivity along the proton axis. The cross peaks in the region around $\delta 53.0$ $50.0 / 3.85-3.25, \delta 52.5-49.8 / 3.25-2.80$, and $\delta 52.4$ 49.5/3.00-2.00 ppm are assigned to triad compositional sequences MMM, MMV, and VMV on the basis of change in intensity with the change in copolymer composition.

The $\beta$-methylene group shows compositional and configurational sensitivity. This region is quite complex and overlapped in both proton and ${ }^{13} \mathrm{C}\left\{{ }^{1} \mathrm{H}\right\}$ NMR. The MM dyad can be resolved with the help of the $\beta$-methylene region of the HSQC spectrum of poly(methyl acrylate). The meso configuration of MM dyad gives two crosspeaks due to two methylene protons having different environment and the racemic configuration gives one crosspeak in between these two crosspeaks. Hence, the cross peaks centered at $\delta$ $35.0 / 1.90$ and $\delta 35.0 / 1.45 \mathrm{ppm}$ are assigned to $\mathrm{MmM}$ dyad and the crosspeak centered at $\delta 35.0 / 1.65 \mathrm{ppm}$ is assigned to MrM dyad as shown in Figure 4a. The MV and the VV dyad regions are overlapped in the HSQC spectra (Figure $4(\mathrm{a}-\mathrm{c})$ and cannot be resolved. However, by comparing the change in the intensity of the crosspeaks with the change in the composition it can be seen that with the addition of the M unit the $\beta$ - methylene region shifts downfield.

\section{D-TOCSY NMR Spectra Studies}

In order to understand the connectivity between the different protons and to confirm the various couplings in the polymer chain, the TOCSY spectra of the copolymers of various compositions were recorded. The expanded TOCSY spectrum $(18 \mathrm{~ms})$ showing the methine and the $\beta$-methylene region of the $\mathrm{V} / \mathrm{M}$ copolymers $\left(F_{\mathrm{V}}=0.14,0.44\right.$, and 0.70$)$ recorded in $\mathrm{CDCl}_{3}$ are shown in Figure $5(\mathrm{a}-\mathrm{c})$, Table III along with the complete signal assignments. The vicinal couplings between the methine protons in both $\mathrm{V}$ and $\mathrm{M}$ centered triads with the methylene protons in VV, MM, and MV dyads in various compositional and configurational sequences can be clearly seen in the TOCSY spectrum. The crosspeaks centered at $\delta 1.90 / 2.30(1), \delta 1.65 / 2.30$ (2), and $\delta 1.45 / 2.30$ (3) ppm are due to coupling of the $\beta$-methylene protons in the MmM (a), MrM and MmM (b) dyads with the methine protons in MMM triad respectively. The crosspeaks centered at $\delta 1.75 / 2.10$ (4), $\delta 1.60 / 2.10$ (5), and $\delta 1.40 / 2.10$ (6) ppm are due to coupling of the $\beta$-methylene protons in the MmM (a), $\mathrm{MrM}$ and MmM (b) dyads with the methine protons in MMV triad respectively. The crosspeaks centered at $\delta$ $2.60 / 4.65$ (7), $\delta 2.30 / 4.65$ (8), and $\delta 2.00 / 4.65$ (9) ppm are due to coupling of the $\beta$-methylene protons in the $\mathrm{MmV}$ (a), MrV and MmV (b) dyads with the methine protons in MVM triad respectively. These crosspeaks do not show any relative changes in intensity with the change in composition hence are assigned to configurational sequences. The crosspeaks $10-13$ show relative change in intensity with the change in copolymer composition and are therefore assigned to compositional sequences. The crosspeaks centered at $\delta 1.40 / 4.10$ (10) and at $\delta 1.80 / 4.40(11) \mathrm{ppm}$ are assigned to the coupling of the $\beta$-methylene protons in the $\mathrm{VV}$ centered tetrads (MVVV and MVVM) respectively with the methine protons in MVV triad and the crosspeaks centered at $\delta 1.85 / 4.10(12)$ and at $\delta 2.00 / 4.40(13) \mathrm{ppm}$ are assigned to the coupling of the $\beta$-methylene protons in the MV centered tetrads (VMVV and MMVV) respectively with the methine protons in MVV. The crosspeak in the region around $\delta 1.90-1.40 / 3.80-3.15$ (14) ppm is assigned to the coupling of the $\beta$-methylene protons in the VV dyad with the methine protons in VVV triad. The crosspeak at $\delta 1.45 / 1.90(15) \mathrm{ppm}$ is assigned to the geminal coupling between the $\beta$-methylene protons (a \& b) of the MmM dyad. These assignments are confirmed by comparing TOCSY NMR spectra of the copolymers of various compositions and that of the corresponding homopolymers. 

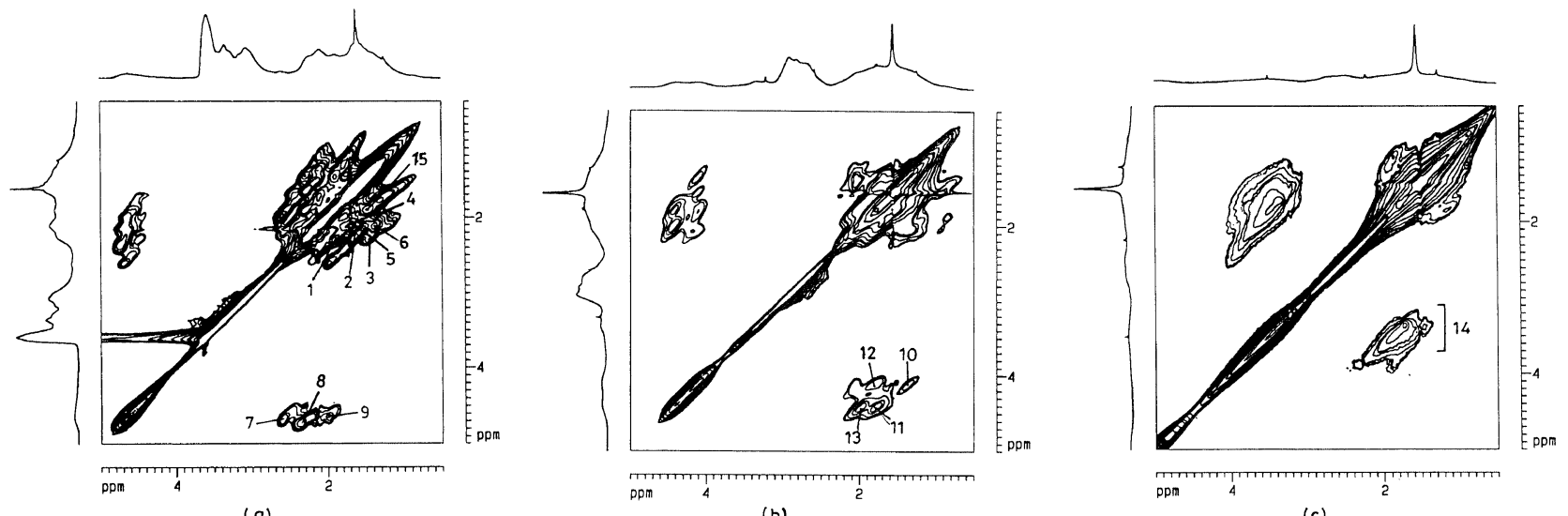

Figure 5. The expanded TOCSY spectrum showing the methine and the $\beta$-methylene region of V/M copolymers of the composition (a) $F_{\mathrm{V}}=0.14$, (b) $F_{\mathrm{V}}=0.44$, and (c) $F_{\mathrm{V}}=0.70$.

Table III. TOCSY ${ }^{1} \mathrm{H}-{ }^{1} \mathrm{H}$ Shift Correlation

\begin{tabular}{clc}
\hline $\begin{array}{c}\text { Peak } \\
\text { No. }\end{array}$ & \multicolumn{1}{c}{ Type of proton (ppm) } & \multicolumn{1}{c}{ Coupled to (ppm) } \\
\hline & Vicinal Couplings between & \\
2 & $\left(\beta-\mathrm{CH}_{2}\right)$ in MmM (a) dyad (1.90) & $(\mathrm{CH})$ in MMM triad (2.30) \\
3 & $\left(\beta-\mathrm{CH}_{2}\right)$ in MrM dyad (1.65) & \\
& $\left(\beta-\mathrm{CH}_{2}\right)$ in MmM (b) dyad (1.45) & \\
5 & $\left(\beta-\mathrm{CH}_{2}\right)$ in MmM (a) dyad (1.75) & $(\mathrm{CH})$ in MMV triad (2.10) \\
6 & $\left(\beta-\mathrm{CH}_{2}\right)$ in MrM dyad (1.60) & \\
7 & $\left(\beta-\mathrm{CH}_{2}\right)$ in MmM (b) dyad (1.40) & \\
8 & $\left(\beta-\mathrm{CH}_{2}\right)$ in MmV (a) dyad (2.60) & $(\mathrm{CH})$ in MVM triad (4.65) \\
9 & $\left(\beta-\mathrm{CH}_{2}\right)$ in MrV dyad (2.30) & \\
10 & $\left(\beta-\mathrm{CH}_{2}\right)$ in MmV (b) dyad (2.00) & $(\mathrm{CH})$ in MVV triad (4.10) \\
11 & $\left(\beta-\mathrm{CH}_{2}\right)$ in MVVV tetrad (1.40) & $(\mathrm{CH})$ in MVV triad (4.40) \\
12 & $\left(\beta-\mathrm{CH}_{2}\right)$ in MVVM tetrad (1.80) & $(\mathrm{CH})$ in MVV triad (4.10) \\
13 & $\left(\beta-\mathrm{CH}_{2}\right)$ in VMVV tetrad (1.85) in MMVV tetrad (2.00) & $(\mathrm{CH})$ in MVV triad (4.40) \\
14 & $\left(\beta-\mathrm{CH}_{2}\right)$ in VV dyad (1.90-1.40) & $(\mathrm{CH})$ in VVV triad (3.80-3.15) \\
15 & $\left(\beta-\mathrm{CH}_{2}\right)$ in MmM dyad (1.45) & \\
\hline
\end{tabular}

\section{CONCLUSIONS}

The monomer reactivity ratios of $N$-vinylcarbazole/ methyl acrylate copolymers are found to be $r_{\mathrm{V}}=0.07 \pm$ $0.03, r_{\mathrm{M}}=0.65 \pm 0.13$ from Kelen-Tudos (KT) and $r_{\mathrm{V}}=0.08, r_{\mathrm{M}}=0.73$ from non-linear error in variable method (EVM). The NMR spectroscopic techniques (DEPT, HSQC, and TOCSY) are used to resolve the overlapping proton and carbon spectra of these copolymers correctly and completely. The methoxy carbon resonance signals of the $\mathrm{M}$ unit and methine carbon resonance signals of both $\mathrm{V}$ and $\mathrm{M}$ unit are assigned to triad compositional sequences and the methylene carbon resonances are assigned to dyad compositional sequences with the help of HSQC and TOCSY NMR spectra of various compositions of the copolymers.

Acknowledgments. The authors wish to thank the Council of Scientific and Industrial Research (CSIR), India for providing the financial support to carry out this work.

\section{REFERENCES}

1. H. Hoegl, J. Phys. Chem., 69, 755 (1965).

2. P. Strohriegl and J. V. Grazulevicius, "Handbook of Organic Conductive Molecules and Polymers", John Wiley \& Sons, Ltd., 1997, vol. 1, p 553.

3. S. Tazake and S. Okamura, "Encyclopedia of Polymer Science and Engineering", Wiley Interscience, New York, N.Y., 1989, vol. 17, p 288.

4. A. M. North and K. E. Whitelock, Polymer, 6, 590 (1968). 
5. J. C. Bevington, C. J. Dyball, and J. Leech, Makromol. Chem., 180, 657 (1979).

6. E. Chiellini, R. Solaro, G. Galli, and A. Ledwith, Macromolecules, 13, 1654 (1980).

7. M. D. Bruch, Macromolecules, 21, 2707 (1988).

8. J. L. Koenig, "Chemical Microstructure of Polymer Chains", Wiley Interscience, New York, N.Y., 1980, p 217.

9. F. A. Bovey and P. A. Mirau, "NMR of Polymers", Academic Press, Inc., New York, N.Y., 1996, p 167.

10. K. Matsuzaki, T. Uryu, and T. Asakura, "NMR Spectroscopy and Stereoregularity of Polymers," Japan Scientific Society Press, Tokyo, 1996, p 173.

11. G. Crone and A. Natansohn, J. Polym. Sci., Part A: Polym.
Chem., 30, 1665 (1992).

12. A. Karali, G. E. Froudakis, and P. Dais, Macromolecules, 33, 3180 (2000).

13. A. S. Brar and M. Kaur, J. Mol. Str., 606, 231 (2002).

14. T. Kelen and F. J. Tudos, J. Macromol. Sci., Chem., A9, 1 (1975).

15. M. Dube, R. A. Sanyel, A. Penlidis, K. F. O'Driscoll, and P. M. Reilly, J. Polym. Sci., Part A: Polym. Chem., 29, 703 (1991).

16. A. S. Brar, K. Dutta, and G. S. Kapur, Macromolecules, 28, 8735 (1995).

17. K. Dutta and A. S. Brar, J. Polym. Sci., Part A: Polym. Chem., 37, 3922 (1999). 